\title{
ABORDAGENS QUANTITATIVAS NA SOCIOLOGIA DA EDUCAÇÃO: análise de produções do GT 14 da ANPEd (2005-2015)
}

\author{
QUANTITATIVE APPROACHES IN SOCIOLOGY OF EDUCATION: \\ ANALYSIS OF WORKS OF GT 14 OF ANPED (2005-2015)
}

\section{ABORDAJES CUANTITATIVOS EN SOCIOLOGÍA DE LA EDUCACIÓN: análisis de producciones del GT 14 de la ANPEd (2005-2015)}

\author{
Jonathan Henriques do Amaral \\ Professor Doutor do Instituto Federal de Educação, \\ Ciência e Tecnologia do Rio Grande do Sul (campus Vacaria) \\ Vacaria -RS, Brasil. \\ jonathan.amaral@vacaria.ifrs.edu.br \\ jhamaral@yahoo.com.br \\ Mónica de la Fare \\ Professora Doutora da Pontifícia
Universidade Católica do Rio Grande do Sul (PUCRS). \\ Porto Alegre - RS, Brasil. \\ monica.fare@pucrs.br
}

Resumo: O objetivo deste artigo foi analisar os usos de abordagens quantitativas em pesquisas da Sociologia da Educação, em um espaço institucional nacional reconhecido por essa área. Para tanto, apresentamos inicialmente uma breve contextualização histórica da Sociologia da Educação no Brasil, para posteriormente introduzir os resultados da análise de trabalhos apresentados no grupo de trabalho em Sociologia da Educação - GT 14 - nas últimas dez reuniões científicas nacionais da Associação Nacional de Pós-Graduação e Pesquisa em Educação - ANPEd, ocorridas no período de 2005 a 2015. A partir da leitura do resumo e das palavras-chave dos 157 trabalhos completos recuperados no repositório institucional dessa associação correspondente ao GT 14, constatamos que $28 \%$ dessas produções $(n=44)$ se valiam de abordagens quantitativas. Após análise desses 44 artigos, identificamos mudanças em relação a estudo anterior sobre o tema: aumento no número de pesquisas elaboradas a partir do uso de abordagens quantitativas; uso frequente de análises de dados secundários provenientes de fontes estatísticas oficiais; emprego de técnicas analíticas sofisticadas, para além da estatística descritiva; e predominância de estudos que usaram exclusivamente dados quantitativos na sua metodologia. As temáticas abordadas dizem respeito a políticas e práticas educacionais, o que confirma o caráter situado das pesquisas desse espaço. Apropriações de contributos de Bernard Charlot em relação ao hibridismo da pesquisa educacional e construtos teóricos de Pierre Bourdieu sobre o campo científico orientaram algumas das reflexões que introduzimos neste artigo.

Palavras-chave: Pesquisa educacional. Sociologia da Educação. Abordagens quantitativas. Campo. Hibridismo. Autonomia.

\begin{abstract}
The aim of this article was to analyze the uses of quantitative approaches in Sociology of Education research in a national institutional space that is recognized by this area. In order to do so, we first present initially a brief historical context of the Sociology of Education in Brazil, to subsequently introduce the results of the analysis of papers presented in the Working Group on Sociology of Education - GT 14 - in the last ten national scientific meetings of Association National of Graduate Course of Research on Education - ANPEd, which occurred in the period from 2005 to 2015. From the reading of the summary and key words of the 157 papers founded in the institutional repository of this association corresponding to the GT-14, we noticed that $28 \%$ of these works $(n=44)$ had used quantitative approaches. After the analysis of these 44 articles, we identified changes in relation to a previous study on the topic: an increasing number of researches using quantitative approaches; the frequent use of analyzes of secondary data from official statistical sources; the use of sophisticated analytical techniques, in addition to descriptive statistics; and predominance of studies that exclusively used quantitative data in their methodology. The subject matter to deal are related to educational politics and practices, which confirms character the position of research in this area. Appropriations of Bernard Charlot's contributions to the hybridity of educational research and theoretical constructs of Pierre Bourdieu's about theorizing on the scientific field have guided some of the reflections we have introduced in this article.
\end{abstract}

Keywords: Educational research. Sociology of Education. Quantitatives approaches. Field. Hybridity. Autonomy.

\footnotetext{
Artigo recebido em setembro de 2017

Aprovado em novembro de 2017
} 
Resumen: El objetivo de este artículo fue analizar los usos de abordajes cuantitativos en investigaciones de la Sociología de la Educación en un espacio institucional nacional reconocido por esa área. Para eso, presentamos inicialmente una breve contextualización histórica de ese campo en Brasil, para posteriormente introducir resultados del análisis de una selección de artículos, basada en la revisión de trabajos presentados en el grupo de trabajo en Sociología de la Educación (GT 14) correspondientes a las Reuniones Científicas Nacionales de la Asociación Nacional de Posgrado e Investigación en Educación (ANPEd) del período 2005-2015. A partir de la lectura de los resúmenes y de las palabras clave de los 157 trabajos localizados en el repositorio institucional de esa asociación fue constatado que $28 \%$ de esos trabajos $(n=44)$ utilizaron abordajes cuantitativos. El análisis de esos 44 artículos permitió identificar transformaciones en relación a resultados presentados por un estudio anterior sobre este tema: aumento de la cantidad de investigaciones elaboradas a partir del uso de abordajes cuantitativas; uso frecuente de análisis de datos secundarios provenientes de estadísticas oficiales; utilización de técnicas analíticas de mayor sofisticación que las de la estadística descriptiva y predominio de estudios que utilizaron exclusivamente abordajes cuantitativos. Las temáticas trabajadas refieren a políticas y prácticas educativas, cuestión que confirma el carácter situado de las investigaciones de ese espacio. Apropiaciones de las contribuciones de Bernard Charlot en relación al hibridismo de la investigación en educación y conceptos de la teorización de Pierre Bourdieu sobre el campo científico orientaron algunas de las reflexiones que se introducen en este artículo.

Palabras clave: Investigación educacional. Sociología de la Educación. Abordajes cuantitativos. Campo. Hibridismo. Autonomía.

\section{INTRODUÇÃO}

Apresentamos neste artigo resultados de uma pesquisa exploratória que buscou analisar o uso de abordagens quantitativas em pesquisas na área de Sociologia da Educação, com o intuito de problematizar aspectos da produção científica desse campo no Brasil. Nosso ponto de partida foi a revisão de produções prévias sobre o tema, tarefa que permitiu identificar um conjunto de trabalhos dedicados à reflexão sobre a produção de conhecimento nessa área, tanto em âmbito internacional (SILVA, 1990) quanto nacional (GOUVEIA, 1985; NEVES, 2002; COSTA; SILVA, 2003; OLIVEIRA; SILVA, 2014; CÊA; SILVA, 2015).

Um aspecto essencial da Sociologia da Educação, reconhecido em todos os trabalhos que revisamos, diz respeito à pluralidade que caracteriza a área. Essa pluralidade se manifesta tanto nas temáticas estudadas pelos pesquisadores do campo quanto nas abordagens teórico-metodológicas por eles utilizadas. Especificamente no caso do Brasil, [...] o interesse pelas políticas educacionais e pelas práticas desenvolvidas nos diversos espaços de ensino e aprendizagem, como a escola, também tem sido uma constante nas pesquisas em Sociologia da Educação, o que demonstra a sensibilidade de pesquisadores da área a circunstâncias extra-acadêmicas (GOUVEIA, 1985; NEVES, 2002).

Uma das afirmações que chamou nossa atenção durante a revisão inicial da literatura sobre o tema foi a referência à escassa utilização de abordagens quantitativas na pesquisa em Educação no Brasil (GATTI, 2004; FERRARO, 2012) e, em especial, na Sociologia da Educação (COSTA; SILVA, 2003). Nosso interesse por esse campo nos levou a problematizar os usos da quantificação em pesquisas desse espaço; assim, o presente trabalho teve por objetivo analisar se o cenário de escassez de estudos quantitativos tem se mantido presente nos últimos anos no campo da Educação - mais especificamente, na Sociologia da Educação.

Uma vez que era inviável revisar o amplo conjunto de produções da Sociologia da Educação no Brasil, e ante a inexistência de publicações periódicas especializadas exclusivamente nessa área no país, decidimos estabelecer um recorte que priorizasse as pesquisas em Sociologia da Educação a partir de um espaço nacional institucionalizado. Para tanto, estabelecemos como foco de análise produções do Grupo de Trabalho 14 (GT 14 - Sociologia da Educação), da Associação Nacional de Pós-Graduação e Pesquisa em Educação (ANPEd), e realizamos um levantamento dos trabalhos completos apresentados nas últimas dez reuniões nacionais promovidas por essa associação'. Essa seleção não pretendeu ser representativa do total da produção da Sociologia da Educação brasileira: limitamo-nos a trabalhar com uma base empírica de um espaço reconhecido, que permitisse potencializar a reflexão sobre algumas tendências da produção desse âmbito.

Um ponto de partida fundamental para nossa pesquisa foi a análise realizada por Costa e Silva (2003) acerca de investigações publicadas no GT 14 entre 1994 e 2001². Nesse sentido, o período

1 Associação Nacional de Pós-Graduação e Pesquisa em Educação, [201-]b.

2 Mais recentemente, Cêa e Silva (2015) realizaram balanço da produção do GT 14 entre 2001 e 2010. No entanto, as autoras não discutiram o uso de abordagens 
de tempo delimitado para nossa pesquisa foi de 2005 a 2015; ; consideramos que, nesse espaço temporal, seria possível identificar tendências em relação ao uso das abordagens metodológicas em questão, assim como constatar a ocorrência de possíveis mudanças em relação a trabalhos publicados em anos anteriores.

As polêmicas sobre o uso de abordagens quantitativas e qualitativas na pesquisa em Educação e nas Ciências Humanas e Sociais, de modo geral, não é nova, constituindo uma das controvérsias dos debates metodológicos contemporâneos. Um dos eixos dessas polêmicas diz respeito à escolha de procedimentos de pesquisa que possam dar conta da relação entre indivíduo e sociedade, a partir de perspectivas centradas no sujeito ou baseadas na estrutura social. Porém, o substrato desses enfrentamentos é ontológico, vinculando-se aos pressupostos do mundo cognoscível (MARRADI; ARCHENTI; PIOVANI, 2007). Nos termos da Sociologia de Pierre Bourdieu, as polêmicas sobre abordagens quantitativas ou qualitativas, assim como as diversas perspectivas teóricas desenvolvidas no interior dessas duas grandes categorias classificatórias, podem ser entendidas como disputas que são tanto epistemológicas quanto políticas, pois "os conflitos epistemológicos são sempre, inseparavelmente, conflitos políticos" (BOURDIEU, 2003, p. 15)4. O autor concebe a ciência como um espaço social de forças em disputa por posições que garantam o monopólio da autoridade científica, e essas lutas envolvem agentes e instituições (BOURDIEU, 1976; 2003).

Ademais, com base em Ferraro (2012), é possível afirmar que a delimitação de fronteiras entre pesquisa quantitativa e qualitativa não constitui tarefa simples, visto que não se pode definir o que é "quantitativo" ou "qualitativo" sem incorrer em certa arbitrariedade. Por um lado, a produção de estatísticas pressupõe que um fenômeno é modelado a partir de classificações, definições, concepções - ou seja, há sempre uma dimensão qualitativa subjacente a dados produzidos quantitativamente. Por outro lado, a pesquisa qualitativa também trabalha com medidas, ainda que aproximadas: quando se afirma que determinado fenômeno é "mais" ou "menos" frequente, também se está procedendo a um tipo de quantificação, ainda que sem o recurso à linguagem matemática. No entanto, existem, sim, diferenças entre abordagens qualitativas e quantitativas (FERRARO, 2012); portanto, para a realização de nosso estudo, foi necessário estabelecer alguns requisitos para a seleção dos trabalhos a serem analisados.

Considerando o estado da discussão sobre o tema aqui abordado e para estabelecer critérios que viabilizassem nossa seleção, selecionamos as pesquisas que envolveram a realização de surveys, com a produção de dados primários, ou estudos que procederam à análise de dados secundários, resultantes de pesquisas e avaliações de organismos oficiais, bancos de dados organizacionais, dentre outros. Mesmo nesse último caso, constatamos que o survey foi o principal método de pesquisa utilizado para a produção dos dados; em menor escala foram utilizados instrumentos como testes cognitivos e provas de aferição de conhecimentos (sobretudo no caso de avaliações oficiais).

Nas Ciências Sociais, o survey tem sido o método de pesquisa mais tradicionalmente utilizado para a produção de dados quantitativos. Especificamente no caso da Sociologia da Educação no Brasil, foi na década de 1960 que se popularizou o uso desse método em pesquisas da área (GOUVEIA, 1985). Segundo Babbie (2001), a pesquisa de survey típica possui algumas características fundamentais, como a seleção de uma amostra de pessoas a serem estudadas; a elaboração e posterior aplicação, a uma amostra populacional, de um questionário para obtenção das informações desejadas; a codificação e quantificação de respostas obtidas; a generalização das conclusões para a população da qual a amostra foi selecionada. No entanto, na prática, o survey se adapta a diferentes tipos de pesquisa, sofrendo modificações em relação às características apontadas anteriormente. Assim, por exemplo, nem sempre se aplicam os questionários a apenas uma amostra estatisticamente representativa de uma população: conforme o tamanho da população a ser estudada, aplicam-se os questionários a todos os seus componentes.

Em nossa seleção, deixamos de lado:

a) produções que apresentassem dados estatísticos (e.g., de recenseamentos) apenas para contextualizar determinado universo de estudo (e.g., etnografias que apresentassem dados estatísticos esparsos, mas não focassem sua análise neles);

quantitativas por parte de pesquisadores do GT

3 De 2005 a 2013 as reuniões nacionais da ANPEd foram realizadas anualmente. Em 2014 e 2016 não houve reuniões. Em outubro de 2017 deverá ocorrer a $38^{a}$ reunião da entidade.

4 As traduções do espanhol ao português neste artigo são de nossa autoria. 
b) estados da arte, a partir dos quais foram quantificadas informações (i.e., produzidas frequências estatísticas);

c) trabalhos que mencionaram ter utilizado abordagens quantitativas, como o survey, mas que, paradoxalmente, não apresentaram nenhum dado quantificado;

d) trabalhos que, embora tenham integrado pesquisas mais amplas, nas quais se produziram ou analisaram dados quantitativos, não se focaram nesses dados, voltando suas análises para os dados qualitativos.

Quanto a isso, convém esclarecer que os trabalhos publicados frequentemente consistem em fragmentos de pesquisas maiores, nas quais foram conjugadas abordagens quantitativas e qualitativas. Todavia, tendo em vista a limitação de espaço e de tempo para apresentação nos encontros do GT, as produções muitas vezes se focam em achados parciais de suas pesquisas. Desse modo, para a análise aqui desenvolvida foram consideradas apenas as informações presentes nas publicações.

Dos 157 trabalhos apresentados no GT 14 entre 2005 e 2015, foram selecionados 44, os quais corresponderam aos nossos critérios de seleção - o que equivale a $28 \%$ do total de artigos. $O$ tratamento dos dados foi inspirado na análise de Ramos Zincke (2005) sobre pesquisas sociológicas chilenas publicadas no início do século XXI. Valendo-se de recursos estatísticos, o autor procedeu à caracterização geral dessas pesquisas, sem que fosse necessária a identificação de sua autoria (RAMOS ZINCKE, 2005). Embora a presente pesquisa não tenha se valido dos mesmos recursos estatísticos empregados pelo sociólogo chileno em seu estudo, foi evitada a identificação dos trabalhos analisados e seus respectivos autores. As produções foram analisadas em suas características gerais, sem que fosse necessário abordar as particularidades de cada publicação. Caso o leitor deste trabalho tenha interesse em averiguar quais investigações foram selecionadas, basta realizar levantamento seguindo os mesmos critérios adotados neste artigo.

Os achados de nossa pesquisa permitiram problematizar a Sociologia da Educação como "campo científico" ou, mais precisamente, como subcampo científico da pesquisa em Educação, a partir de usos e apropriações de construtos teóricos da Teoria dos Campos de Bourdieu (1976, 2003, 2008). As teorizações desse autor problematizam a ciência como um espaço de lutas, com uma autonomia relativa - um "microcosmo dotado de suas próprias leis", mas que não escapa às imposições do macrocosmo. $\mathrm{O}$ autor adverte que qualquer campo é objeto de disputas, "tanto em sua representação como em sua realidade" (BOURDIEU, 2003, p. 74-75). Trata-se de pensar em termos de uma dinâmica de relações objetivas e posições adquiridas:

O que está em jogo especificamente nessa luta é o monopólio da autoridade científica definida, de maneira inseparável, como capacidade técnica e poder social; ou, se quisermos, o monopólio da competência científica, compreendida enquanto capacidade de falar e de agir legitimamente (isto é, de maneira autorizada e com autoridade), que é socialmente outorgada a um agente determinado. (BOURDIEU, 1976, p. 2).

Defendemos que a utilização desses conceitos para a compreensão do campo da pesquisa educacional exige prudência e reflexão, tendo em vista as diferenças entre, por um lado, o campo de proveniência dessa teoria e seu objeto de análise (qual seja, a ciência francesa, com foco nas Ciências Exatas e Naturais) e, por outro lado, o campo da pesquisa educacional no Brasil. Abordamos essa questão neste artigo apenas de modo introdutório; esperamos aprofundá-la em produções posteriores.

A discussão a seguir está organizada em duas subseções. Na primeira delas, realizamos uma breve contextualização histórica da Sociologia da Educação no Brasil, buscando não perder de vista as características do espaço maior em que essa área se insere - qual seja: o campo da pesquisa em Educação. Posteriormente, apresentamos uma análise das produções selecionadas em nosso estudo, trabalhando o contraste com resultados de pesquisas anteriores e incluindo a descrição dos diferentes usos da quantificação como recurso metodológico, assim como a agenda de temas que essas produções abordam. Também refletimos sobre características da produção científica em Educação, considerando aspectos como o reconhecimento da autoridade científica, capital científico e autonomia, a partir de algumas contribuições provenientes da teorização de Bourdieu. 


\title{
2 A sociologia da educação e a pesquisa educacional no Brasil
}

A pesquisa educacional se caracteriza pela heterogeneidade de perspectivas teóricometodológicas e pelo entrecruzamento de saberes oriundos de campos disciplinares distintos, práticas pedagógicas e políticas educacionais (PLAISANCE; VERGNAUD, 2003; CHARLOT, 2006). Ao reconhecer que esse hibridismo se constitui em um aspecto basilar do campo da Educação, Charlot (2006, p. 9) propôs a seguinte definição para o que seria essa área do conhecimento:

\begin{abstract}
O que é específico da educação como área de saber é o fato de ela ser uma área na qual circulam, ao mesmo tempo, conhecimentos (por vezes de origens diversas), práticas e políticas. Delimita-se assim uma primeira definição da disciplina educação ou ciências da educação: é um campo de saber fundamentalmente mestiço, em que se cruzam, se interpelam e, por vezes, se fecundam, de um lado, conhecimentos, conceitos e métodos originários de campos disciplinares múltiplos, e, de outro lado, saberes, práticas, fins éticos e políticos. O que define a especificidade da disciplina é essa mestiçagem, essa circulação.
\end{abstract}

A constituição do campo da pesquisa em Educação no Brasil é ilustrativa dessa intersecção entre conhecimentos, políticas e práticas que caracterizam a área. De acordo com Gatti (2001), a criação do Instituto Nacional de Pedagogia (INEP), em 1937 - o qual, no ano seguinte, recebeu a denominação de Instituto Nacional de Estudos Pedagógicos e, em 1972, de Instituto Nacional de Estudos e Pesquisas Educacionais ${ }^{5}$ - representou um fato significativo para o início da pesquisa educacional no país. Em seus primórdios, os objetivos do Instituto abrangiam, dentre outros aspectos, a assessoria técnica aos serviços de educação municipais, estaduais e particulares e o desenvolvimento de estudos que pudessem subsidiar a formulação de políticas educacionais ${ }^{6}$.

Também foi fundamental para a institucionalização da pesquisa em Educação no Brasil a criação dos Centros de Pesquisas Educacionais do INEP, os quais passaram a funcionar a partir de 1955. Com sedes no Distrito Federal (atual estado do Rio de Janeiro) e em mais cinco estados (São Paulo, Bahia, Rio Grande do Sul, Minas Gerais e Pernambuco), os Centros integravam um conjunto de medidas governamentais voltados à pesquisa e ao planejamento. Nesse contexto, a educação era entendida como problema nacional, e a administração pública passava por um processo de racionalização. Portanto, a criação de órgãos orientados à pesquisa esteve vinculada ao objetivo de modernização do Estado brasileiro; o desenvolvimento da pesquisa era estratégico para se atingir esse propósito, pois o estudo e a compreensão dos problemas educacionais do país poderiam fornecer subsídios para a sua superação (FERREIRA, 2007).

Em seus primórdios, o INEP se especializou em atividades que visavam à construção de um modelo nacional de ensino e à expansão da escolarização. Já a criação dos Centros pressupunha o interesse em compreender as particularidades de cada região do país, de modo a se desenvolverem políticas que contemplassem essas especificidades. As diretrizes de trabalho dos Centros enfatizavam a importância do instrumental teórico-metodológico das Ciências Sociais para a realização de pesquisas que fundamentassem as tomadas de decisão no setor educacional. Entretanto, nem todos os estudos desenvolvidos nos Centros estavam embasados nas Ciências Sociais (FERREIRA, 2007).

A institucionalização da pesquisa educacional no meio universitário passou a se dar apenas a partir dos anos 1960, com a criação dos primeiros cursos de pós-graduação em Educação, o que implicou a intensificação do desenvolvimento da área. Nesta época formularam-se programas de incentivo à formação de profissionais no exterior, com a posterior absorção desses profissionais nos cursos recém-criados (GATTI, 2001).

A produção internacional referida a temas da pesquisa em Educação reconhece que, dentre as áreas que fornecem as matrizes epistemológicas para essas produções, a Sociologia ocupa lugar relevante (PLAISANCE; VERGNAUD, 2003) e que "a Sociologia da Educação é um campo de trabalho variado, confuso, dinâmico, um pouco ilusório e invariavelmente conflituoso" (APPLE; BALL; GANDIN, 2013, p. 17). Especificamente no Brasil, a história do surgimento da Sociologia da Educação se confunde com a própria história da emergência das Ciências Sociais no país, tendo em vista que os primeiros pesquisadores sociais brasileiros levaram a cabo estudos sobre educação. Ademais, foi a partir da década de 1930 que começaram a se delinear trabalhos de Sociologia da

5 Hoje denominado Instituto Nacional de Estudos e Pesquisas Educacionais Anísio Teixeira, em homenagem ao educador que dirigiu o Instituto na década de 1950. 6 Instituto Nacional de Estudos e Pesquisas Educacionais Anísio Teixeira, 2015a. 
Educação no Brasil - portanto, no mesmo período em que a pesquisa educacional começava a se constituir, desenvolvida em organismos oficiais. Nesse sentido, os estudos sociológicos sempre foram constituintes da produção de conhecimento em Educação brasileira (NEVES, 2002; COSTA; SILVA, 2003).

Reconhecidos sociólogos brasileiros debateram as especificidades da Sociologia da Educação nos primórdios da área. Antonio Candido, em 1955, analisava as tendências do desenvolvimento desse campo, atribuindo-lhe uma especificidade associada "à preocupação com a função social da educação e com a solução dos problemas educacionais" (CANDIDO, 1978, p. 9), distante tanto da sociologia norte-americana de orientação prática quanto das reflexões sobre "o caráter social do processo educativo, seu significado como sistema de valores sociais, sua relação com as concepções e teorias do homem" (CANDIDO, 1978, p. 7). Como exemplo dessas perspectivas, o autor apresenta as teorias de Émile Durkheim e de John Dewey.

$\mathrm{Na}$ década de 1960, Florestan Fernandes fazia uma crítica às tentativas de subdivisão do campo da Sociologia por meio das denominadas "Sociologias especiais" (incluída aí a Sociologia da Educação), cada uma com objetos e problemas próprios (FERNANDES, 1978b, p. 6). No entanto, o autor reconhecia que o uso dessas expressões facilitava o reconhecimento e a identificação das contribuições intelectuais nas relações entre autor e público, encontrando nessa razão uma adequada justificativa para o uso desses termos. Ademais, em seu artigo sobre o dilema educacional brasileiro, Fernandes (1978a) enfatizava a participação dos cientistas sociais na reconstrução do sistema educativo do país e destacava o papel dos sociólogos e dos conhecimentos sociológicos nos planos de controle educacional dos Centros Brasileiros de Pesquisas Educacionais do INEP (FERNANDES, 1978a).

As contribuições de Antonio Candido e Florestan Fernandes podem ser situadas na primeira fase da produção sociológica sobre educação no Brasil, correspondente aos primeiros passos da Sociologia da Educação. Segundo Neves (2002), essa primeira etapa se estendeu de 1930 a 1960 e foi caracterizada pelo forte engajamento político e pelo envolvimento com os problemas educacionais aqui existentes, assim como pelo desenvolvimento da pesquisa em organismos oficiais (como 0 INEP), pela consideração da educação como área estratégica para o desenvolvimento do país e, como consequência, pela realização de estudos que pudessem subsidiar a elaboração de políticas públicas. Esses estudos se valeram do uso frequente da estatística para produzir diagnósticos dos problemas do sistema educacional brasileiro (NEVES, 2002).

Uma segunda fase é caracterizada por essa autora como sendo a do pessimismo pedagógico. Essa fase coincide com o período da ditadura militar, durante o qual houve a desestruturação dos primeiros organismos oficiais de estudos em educação, como o INEP. O foco das pesquisas desenvolvidas nessa época era a política educacional levada a cabo pelos militares, como as leis e os programas governamentais que foram criados. Com forte influência das chamadas teorias da reprodução, os pesquisadores eram céticos em relação a essas iniciativas, pois acreditavam que "as políticas e os sistemas educacionais simplesmente reproduziam as estruturas de dominação, não alterando as condições de vida ou o sistema de poder na sociedade" (NEVES, 2002, p. 360). Nesse sentido, foram frustradas as expectativas de transformação da realidade educacional nutridas pelos sociólogos da Educação no período anterior.

Já a fase atual de produção de conhecimento em Sociologia da Educação começa em meados dos anos 1980, estendendo-se até os dias de hoje. Essa fase é caracterizada por grande diversificação temática e teórico-metodológica, ao contrário dos estudos realizados nas fases antecedentes. Portanto, assim como o campo da pesquisa educacional, de maneira mais ampla, a Sociologia da Educação também se caracteriza pela heterogeneidade, tanto no Brasil quanto internacionalmente (SILVA, 1990; NEVES, 2002).

A importância da abordagem sociológica para a pesquisa educacional pode ser constatada no fato de que a ANPEd - um dos principais espaços de produção e disseminação de conhecimento em Educação no país - conta com um Grupo de Trabalho em Sociologia da Educação desde 1990 - o GT 14. O grupo, que começou a funcionar em caráter experimental em 1989, foi oficializado no ano seguinte, tendo na escola um dos seus principais focos de estudo. Temáticas como desigualdades no acesso a oportunidades educacionais, relações entre família e escola e diferenças de gênero têm sido abordadas tradicionalmente por pesquisadores do grupo, no qual se verifica a tendência 
à realização de estudos empíricos que buscam conjugar a análise de fenômenos macrossociais a estudos qualitativos focados nos processos microssociais e escolares ${ }^{7}$.

No início do século XXI, Costa e Silva (2003) procederam a um balanço dos trabalhos apresentados no GT 14 entre 1994 e 2001. Nesse balanço, os autores constataram a baixa realização de trabalhos quantitativos e a "total ausência" (COSTA; SILVA, 2003, p. 115) de trabalhos que tivessem utilizado fontes estatísticas secundárias, como dados censitários, e procedimentos analíticos mais sofisticados no tratamento de dados, para além da estatística descritiva. Conforme os autores, esse cenário poderia estar vinculado ao preconceito existente na Educação quanto à pesquisa quantitativa, muitas vezes tachada - equivocadamente - de "conservadora" ou "positivista". Em seu levantamento, os pesquisadores verificaram o predomínio de estudos de caso, o que traria consequências problemáticas para os estudos da área: certos fenômenos deixariam de ser compreendidos como parte de um contexto social mais amplo, e generalizações indevidas poderiam ser realizadas, uma vez que não se utilizariam os recursos adequados para tanto (COSTA; SILVA, 2003).

A escassez de estudos realizados a partir de abordagens quantitativas não é exclusividade da Sociologia da Educação, mas da pesquisa educacional em sua totalidade. Embasando-se em levantamento de trabalhos publicados nos principais periódicos do campo educacional, Gatti (2004) afirma que, à exceção de estudos realizados por organismos oficiais (como as avaliações de rendimento escolar desenvolvidas por sistemas educacionais), são raros os trabalhos em Educação que empreguem metodologias quantitativas. Para a pesquisadora, desde os anos 1980 a formação em pesquisa no campo tem preterido o estudo dessas metodologias, o que implica o surgimento de duas posturas equivocadas: a) a aceitação acrítica de dados estatísticos e b) a crítica - também constatada por Costa e Silva (2003) - mal fundamentada à pesquisa quantitativa, concebida como "conservadora" ou "positivista".

Quanto a isso, cabe lembrar que muitas pesquisas qualitativas que reivindicam o rótulo de "pós-modernas" e apresentam esse tipo de crítica aos estudos quantitativos incorrem no mesmo tipo de equívoco que tentam problematizar. Há trabalhos que se limitam à realização de descrições de uma realidade tomada como "dado", supostamente apreendida sem a intermediação de um repertório teórico, a partir do qual interpretá-la e produzir teorizações sobre ela - o que constitui uma manifestação de positivismo. Entretanto, os significados nunca estão "evidentes" nos objetos estudados: mais do que "coletar" significados dados de antemão, o pesquisador interpreta seus objetos de estudo, com base em um repertório teórico que lhe permite ver certos elementos, em detrimento de outros (FLECK, 1986).

Para Gatti (2004), conquanto sejam recorrentes as afirmações de que até meados do século XX predominavam no Brasil os estudos quantitativos em Educação, as abordagens quantitativas nunca constituíram tradição forte na área; mesmo os poucos trabalhos que empregavam essas abordagens se limitavam à análise descritiva de tabelas de frequências, sendo raros os estudos que procedessem a análises estatísticas mais refinadas. Portanto, nunca existiu uma tradição consolidada de pesquisa quantitativa no campo da Educação, o que se constitui em um problema, tendo em vista que, sem dados quantitativos, não é possível ter a real dimensão dos fenômenos educacionais, de modo a desmistificar preconceitos e opiniões embasados muito mais em convicções políticas do que em dados consistentes (GATTI, 2004). Na mesma direção, Ferraro (2012) argumenta que foi a partir da década de 1980 que passou a haver um desencanto crescente, na área da Educação, com a pesquisa quantitativa e até mesmo com a utilização de dados estatísticos elementares. Por um lado, isso levou ao desenvolvimento de abordagens qualitativas e ao reconhecimento de sua legitimidade no campo educacional; por outro, implicou a supressão de disciplinas de estatística dos cursos de graduação em Pedagogia e de pós-graduação em Educação. Isso explicaria as deficiências verificadas entre pesquisadores da área em relação à pesquisa quantitativa.

Todavia, a carência na formação em estatística e pesquisa quantitativa não é restrita ao campo da Educação, mas um fenômeno geral nas Ciências Humanas e Sociais. Baquero (2009) afirma que, tradicionalmente, os métodos quantitativos têm sido vistos com desconfiança por pesquisadores sociais latino-americanos: acredita-se que os fenômenos sociais são mais bem explicados a partir de estudos qualitativos, de modo que se criou uma dicotomia entre um e outro tipo de método. Nas palavras do pesquisador, "os quantitativistas argumentam que seus dados são rigorosos, críveis e

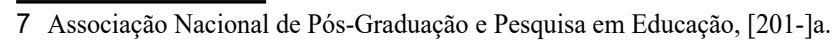


científicos. Os qualitativistas propõem que seus dados são sensitivos, detalhados e contextuais" (BAQUERO, 2009, p. 09).

Para o autor, dados quantitativos e qualitativos não se opõem, mas se complementam: os primeiros são formulados a partir de julgamentos qualitativos, enquanto os segundos podem ser descritos e manipulados quantitativamente. Além disso, os fenômenos humanos e sociais podem ser interpretados de maneiras diversas, e a conjugação dos dois tipos de abordagem possibilita uma interpretação mais refinada da realidade. Contudo, Baquero (2009) menciona que até mesmo pesquisadores com doutorado na área de Ciências Sociais desconhecem os procedimentos da pesquisa quantitativa ou não sabem interpretar dados dessa natureza; assim, esses pesquisadores tendem a simplesmente desqualificar esse tipo de trabalho. Essa constatação justifica a necessidade de uma formação sólida tanto em pesquisa qualitativa quanto em pesquisa quantitativa, de modo a conhecer suas potencialidades e limites e a evitar julgamentos de valor equivocados em relação às duas formas de produção de conhecimento (BAQUERO, 2009).

Na seção a seguir, são apresentados os principais dados obtidos a partir do levantamento. Para os propósitos deste estudo, foi suficiente analisar frequências simples, embora reconheçamos que trabalhos quantitativos não se limitam à estatística descritiva, podendo ser realizadas análises com correlação de variáveis, estimação de modelos de regressão logística, dentre outras modalidades - fato que não diminui a importância e a potencialidade da descrição e análise de frequências estatísticas para a compreensão de determinados objetos de estudo.

\section{CARACTERIZAÇÃO DOS TRABALHOS QUANTITATIVOS DO GT 14 ENTRE 2005 E 2015}

Se autores como Costa e Silva (2003) e Gatti (2004) haviam constatado em suas análises a escassez de trabalhos quantitativos no campo educacional, é possível perceber que, ao menos no GT 14, tem havido indícios de mudança nesse fenômeno. Conquanto os trabalhos qualitativos constituam a maioria das pesquisas apresentadas no GT 14 entre 2005 e 2015, o número de trabalhos quantitativos $(n=44)$ não é pouco expressivo, principalmente se se considerar a parca tradição de pesquisa quantitativa na área. A tabela abaixo apresenta o número de trabalhos selecionados para análise, de acordo com o ano de sua publicação:

Tabela 1 - Número de trabalhos selecionados para análise (2005-2015)

\begin{tabular}{cccc}
\hline Ano de publicação & $\mathbf{N}$ & $\mathbf{n}$ & $\mathbf{\%}$ \\
\hline 2005 & 11 & 2 & $18,18 \%$ \\
2006 & 19 & 4 & $21,05 \%$ \\
2007 & 11 & 4 & $36,36 \%$ \\
2008 & 16 & 0 & $0,00 \%$ \\
2009 & 15 & 3 & $20,00 \%$ \\
2010 & 17 & 5 & $29,41 \%$ \\
2011 & 13 & 7 & $53,85 \%$ \\
2012 & 17 & 5 & $29,41 \%$ \\
2013 & 17 & 5 & $29,41 \%$ \\
2015 & 21 & 9 & $42,86 \%$ \\
\hline Total & $\mathbf{1 5 7}$ & $\mathbf{4 4}$ & $\mathbf{2 8 , 0 3 \%}$ \\
\hline
\end{tabular}

Fonte: Elaborado pelos autores.

Em média, foram apresentados por encontro do GT 14 quatro trabalhos completos com algum tipo de abordagem quantitativa, o que equivale a $28 \%$ do total. 2008 foi o único ano em que não foi publicado nenhum estudo com as características definidas para seleção. Os anos em que houve maior número de trabalhos quantitativos foram 2011, com aproximadamente $54 \%$ (único ano em que a maioria dos trabalhos apresentados contou com algum tipo de abordagem quantitativa), e 2015, com aproximadamente $43 \%$.

Em relação às temáticas, verificamos a recorrência de cinco grandes temas, a partir dos quais categorizamos os artigos. Embora as temáticas possam se sobrepor em um mesmo trabalho, as publicações foram classificadas de acordo com a temática predominante. O quadro a seguir apresenta cada um dos cinco grandes temas e sua respectiva descrição. 
Quadro 1 - Temáticas conforme as quais os trabalhos foram categorizados

\begin{tabular}{|l|l|}
\hline \multicolumn{1}{|c|}{ Categoria } & \multicolumn{1}{c|}{ Descrição } \\
\hline $\begin{array}{l}\text { Relações de alunos com seus processos de } \\
\text { escolarização }\end{array}$ & $\begin{array}{l}\text { Percepções de alunos sobre a escola; suas formas de se } \\
\text { relacionar com a aprendizagem e o conhecimento; suas } \\
\text { expectativas em relação à sua formação; suas práticas de } \\
\text { estudo; suas trajetórias escolares. }\end{array}$ \\
\hline Relações entre família e escola & $\begin{array}{l}\text { Participação de pais na gestão escolar; fatores que interferem } \\
\text { na escolha de escolas; concepções e práticas em relação } \\
\text { aos deveres de casa; coincidência entre os processos de } \\
\text { socialização de família e escola; influência da família no no } \\
\text { desempenho escolar dos filhos. }\end{array}$ \\
\hline Insucesso escolar & $\begin{array}{l}\text { Evasão escolar; reprovação. } \\
\text { Critérios ligados à alocação de professores em escolas; } \\
\text { relações entre o “estilo" de gestão de escolas e o sucesso de } \\
\text { seus alunos em avaliações oficiais; organização de turmas e } \\
\text { desempenho escolar. }\end{array}$ \\
\hline Desigualdades escolar & $\begin{array}{l}\text { Influência das condições socioeconômicas no desempenho } \\
\text { escolar, no acesso ao ensino superior, no acesso a bens } \\
\text { culturais. }\end{array}$ \\
\hline
\end{tabular}

Fonte: Elaborado pelos autores.

A categoria conforme a qual classificamos o maior número de estudos foi a primeira: $34 \%(n=15)$ dos trabalhos selecionados abordam as relações de alunos com seus processos de escolarização. A segunda temática mais recorrente foram as relações entre família e escola, com $25 \%$ dos trabalhos $(n=11)$. Em seguida, aparecem as investigações que abordam o insucesso escolar, com aproximadamente $16 \%(n=7)$; desigualdades e educação, com $14 \%(n=6)$; e, por fim, gestão escolar, temática abordada em $11 \%$ dos trabalhos $(n=5)$. A tabela abaixo compila essas informações.

Tabela 2 - Temáticas recorrentes nos trabalhos (2005-2015)

\begin{tabular}{rcc}
\hline \multicolumn{1}{c}{ Temáticas } & $\mathbf{n}$ & $\mathbf{\%}$ \\
\hline Relações de alunos com seus processos de escolarização & 15 & $34,09 \%$ \\
Relações entre família e escola & 11 & $25,00 \%$ \\
Insucesso escolar & 7 & $15,91 \%$ \\
Desigualdades e educação & 6 & $13,64 \%$ \\
Gestão escolar & 5 & $11,36 \%$ \\
\hline Total & $\mathbf{4 4}$ & $\mathbf{1 0 0 , 0 0 \%}$ \\
\hline
\end{tabular}

Fonte: Elaborado pelos autores.

A partir de apropriações da teorização de Bourdieu sobre os campos científicos, Oliveira e Silva (2014) afirmam que a Sociologia da Educação, bem como o próprio campo da pesquisa educacional no Brasil, seriam dotados de baixa autonomia, tendo em vista sua dificuldade em refratar influências "externas" à produção de conhecimento, como interesses econômicos e políticos. Essa baixa autonomia seria explicada pela heterogeneidade temática da Sociologia da Educação, pelo forte vínculo com problemas educacionais do país e pela dificuldade em consolidar uma agenda nacional de pesquisa (OLIVEIRA; SILVA, 2014). Porém, como destaca Bourdieu (2003), não se trata de pensar o mundo científico em termos do binômio "ciência pura/ciência servil" - a primeira livre de toda necessidade social e a segunda submetida a todas as exigências político-econômicas -, e sim de interrogar como as coações e demandas que o mundo social exerce são mediadas pela lógica do próprio campo. Ademais, Bourdieu (2008) afirma que o campo científico é dotado de autonomia relativa com relação a outras esferas do mundo social. Essa autonomia relativa é garantida pela existência de critérios que tornam extremamente seletiva a admissão nesse campo: o ingresso na ciência depende da competência teórica - isto é, do domínio intelectual sobre teorizações complexas - e da incorporação dessa competência no exercício de certas práticas - por exemplo, no manejo de instrumentos utilizados em laboratório.

De fato, ao analisar as temáticas predominantes nos trabalhos do GT 14 entre 2005 e 2015, é possível constatar que as preocupações de pesquisadores da área se voltam, em linhas gerais, para as práticas educativas desenvolvidas em diferentes instituições - sobretudo a escola e a família - 
e as políticas públicas levadas a cabo no setor educacional. No entanto, considerando o histórico do campo da pesquisa educacional e da Sociologia da Educação no Brasil, cabe questionar: seria possível que essas duas áreas se constituíssem como campos científicos "autônomos", nos termos definidos por Bourdieu? Mais do que isso, até que ponto o pensamento desse autor é pertinente para a análise dos processos de pesquisa e produção de conhecimento em Educação, se se considerar o hibridismo destacado por Charlot (2006) em sua definição de pesquisa educacional já citada neste trabalho?

Trata-se de problema complexo, cuja abordagem foge dos propósitos deste artigo. Por ora, cabe ressaltar - mais uma vez - que tanto o hibridismo como a convivência (muitas vezes conflituosa) e o atravessamento de distintas tradições disciplinares são marcas fundamentais do campo da Educação, e que a constituição dessa área de pesquisa no Brasil se deu em estreita ligação com organismos oficiais, com o intuito de produzir conhecimentos que pudessem subsidiar a formulação de políticas públicas (GATTI, 2001; COSTA; SILVA, 2003; FERREIRA, 2007). Além disso, no campo da Educação, as atividades de pesquisa frequentemente convergem com a atuação profissional: muitos pesquisadores atuam como professores e pesquisam sobre a realidade em que trabalham (DE LA FARE; CARVALHO, 2017) - o que também auxilia a compreender o interesse por temáticas supostamente "externas" à área. Por fim, as tentativas de demarcar a possível especificidade e as possíveis fronteiras do campo da pesquisa educacional esbarram na arbitrariedade, pois os entendimentos sobre qual seria o "verdadeiro" objeto de estudo da Educação ou até mesmo sobre o que pode ser considerado "educativo" são divergentes (PLAISANCE; VERGNAUD, 2003).

A concepção de autonomia científica do campo educacional pode ser questionada até mesmo pelo fato de que certos estudos da área - ao menos no GT 14 - analisam dados secundários, oriundos não de pesquisas acadêmicas, mas de estudos realizados por organismos estatais voltados, portanto, à elaboração de políticas públicas. Esse é o caso de aproximadamente $32 \%$ $(n=14)$ dos trabalhos analisados para este artigo, os quais utilizaram apenas dados secundários, oriundos de censos do IBGE (Instituto Brasileiro de Geografia e Estatística) e/ou de avaliações de larga escala (Sistema de Avaliação da Educação Básica - SAEB'; Prova Brasil9; Programme for International Student Assessment - PISA ${ }^{10}$; avaliações do ensino superior realizadas no Brasil em diferentes momentos históricos); além de bancos de dados de estabelecimentos de ensino e secretarias (estaduais e municipais) de educação. Entretanto, esse tipo de trabalho não constitui a maioria das publicações selecionadas, pois $61 \%(n=27)$ trabalharam somente com dados primários, gerados pelos próprios pesquisadores. Nesse caso, o survey foi o recurso utilizado para obtenção das informações desejadas; apenas um trabalho relatou o uso de instrumento cognitivo (teste de avaliação), conjugado com questionário. Três trabalhos (7\%) procederam à análise dos dois tipos de dados. Também aqui é possível vislumbrar uma mudança em relação ao estudo de Costa e Silva (2003): se os autores constataram a total ausência, entre os anos de 1994 a 2001, de produções do GT 14 que fizessem uso de dados secundários, não se pode afirmar o mesmo em relação aos trabalhos apresentados entre 2005 e 2015.

A tabela 3 sintetiza as informações descritas no parágrafo anterior:

Tabela 3 - Tipo de dados analisados nos trabalhos (2005-2015)

\begin{tabular}{ccc}
\hline Tipo de dados & $\mathbf{n}$ & $\mathbf{\%}$ \\
\hline Primários & 27 & $61,36 \%$ \\
Secundários & 14 & $31,82 \%$ \\
Ambos & 3 & $6,82 \%$ \\
\hline Total & $\mathbf{4 4}$ & $\mathbf{1 0 0 , 0 0 \%}$
\end{tabular}

Fonte: Elaborado pelos autores.

Dos 44 trabalhos selecionados, mais da metade (aproximadamente 61\%, ou 27 trabalhos, em números absolutos) se valeu somente de abordagens quantitativas, enquanto aproximadamente

8 Instituído em 1990, o SAEB é composto por diferentes avaliações de larga escala, as quais se propõem a realizar um diagnóstico da educação básica brasileira e dos fatores que interferem no aprendizado dos alunos. (INSTITUTO NACIONAL DE ESTUDOS E PESQUISAS EDUCACIONAIS ANÍSIO TEIXEIRA, 2017).

9 A Avaliação Nacional do Rendimento Escolar - Prova Brasil - é uma das avaliações que integram o SAEB. Trata-se de avaliação censitária realizada a cada biênio, envolvendo alunos do $5^{\circ}$ e $9^{\circ}$ anos do Ensino Fundamental, matriculados em escolas públicas que tenham ao menos 20 alunos em cada ano avaliado. A prova mensura o conhecimento dos alunos em Língua Portuguesa e Matemática, além de apresentar indicadores relacionados às condições externas e internas que interferem no trabalho das escolas. (INSTITUTO NACIONAL DE ESTUDOS E PESQUISAS EDUCACIONAIS ANÍSIO TEIXEIRA, 2015b).

10Trata-se de survey internacional realizado pela Organização para a Cooperação e Desenvolvimento Econômico (OCDE) a cada triênio, com o objetivo de avaliar os sistemas educacionais ao redor do mundo, a partir de habilidades e conhecimentos obtidos por alunos de 15 anos de idade, em áreas como ciências, matemática, leitura, resolução de problemas e alfabetização financeira. (OECD, 2017). 
$39 \%(n=17)$ conjugaram abordagens quantitativas com informações geradas por técnicas qualitativas, como análise documental, entrevista, observação participante, produção textual. No caso do primeiro grupo de trabalhos, cabe ressaltar que alguns deles integravam pesquisas mais abrangentes, que também envolveram abordagens qualitativas; contudo, no trabalho apresentado no GT 14 (e, portanto, selecionado para nossa análise), o foco era em dados quantitativos. De qualquer maneira, as estatísticas descritas neste parágrafo também demonstram mudanças em relação aos trabalhos do GT 14 analisados por Costa e Silva (2003), bem como em relação ao campo da pesquisa educacional, de maneira mais ampla.

Outra modificação em relação à análise de Costa e Silva (2003) diz respeito às estratégias empregadas nos trabalhos do GT 14 para o tratamento e a análise dos dados quantitativos. Se naquela ocasião os autores haviam constatado a inexistência de trabalhos que se valessem de estratégias analíticas mais refinadas, não se pode afirmar o mesmo em relação aos trabalhos publicados entre 2005 e 2015: embora a estatística descritiva seja a modalidade empregada na maioria dos trabalhos (52\%), $48 \%$ das pesquisas se valeram de outras técnicas de análise, como criação de índices; estimação de modelos de regressão logística; análise de conglomerados; análise multifatorial; análise de correlação. Conquanto esse tipo de análise não constitua a maioria dos trabalhos selecionados, a diferença em relação às publicações que empregaram apenas a descrição de frequências é de somente $4 \%$. Logo, mesmo que esses trabalhos formem apenas uma pequena amostra das pesquisas realizadas no campo da pesquisa educacional, eles podem ser tomados como indicativos da existência de um processo de mudança, não só em relação à Sociologia da Educação mas também em relação ao campo da Educação como um todo.

\section{CONSIDERAÇÕES FINAIS}

A investigação apresentada neste artigo demonstrou a ocorrência de transformações nos trabalhos do GT 14 da ANPEd. Levando em conta a análise de Costa e Silva (2003) sobre esse mesmo grupo, foram constatadas modificações em relação à frequência de trabalhos quantitativos; ao tipo de análise empregado; à realização de análises de dados secundários. Trata-se de mudanças relevantes para o campo da Educação como um todo, se se considerar a escassa tradição de estudos quantitativos na área (GATTI, 2004; FERRARO, 2012).

$O$ vínculo da pesquisa em Educação com práticas e políticas educacionais também foi verificado neste trabalho, o que mostra que essa "condição mestiça", como denomina Charlot (2006), segue sendo uma marca importante da área. Torna-se questionável, pois, a concepção de que a falta de autonomia científica do campo da pesquisa educacional - e da Sociologia da Educação, mais especificamente - se constituiria em um problema, tal como compreendem Oliveira e Silva (2014). Levando em conta a história e as particularidades da área, poderíamos dizer que a busca pela autonomia implicaria a perda do que é mais específico ao campo da Educação. Ademais, essa condição mestiça não é exclusividade dessa área, pois é compartilhada por outras disciplinas também envolvidas com a formação de pessoal engajado em atividades práticas, como a Administração, a Ciência Política e a Medicina (PLAISANCE; VERGNAUD, 2003; CHARLOT, 2006).

Tendo em vista a complexidade e a diversidade dos fenômenos estudados no campo Educacional, não se trata de afirmar que as abordagens quantitativas sejam "superiores" às qualitativas, ou vice-versa. Como lembra Ferraro (2012, p. 143), "é na construção do objeto ou do problema de pesquisa que se poderá definir o método ou a combinação de métodos e técnicas a empregar na investigação". Se a pesquisa quantitativa apresenta limites, eles também estão presentes na pesquisa qualitativa, e, como já foi advertido, aquilo que necessita ser escrutado "e neutralizado, no ato mesmo da construção do objeto, é o inconsciente científico coletivo fixado às teorias, problemas e categorias (especialmente as nacionais) do juízo acadêmico" (BOURDIEU; WACQUANT, 2005, p. 75). Não há "fórmula" simplista que possa indicar como conjugar abordagens quantitativas e qualitativas ou em que tipo de situação é conveniente unir as duas abordagens: tais escolhas dependem dos objetivos, do referencial teórico, do problema de cada investigação, além das condições materiais sob as quais cada trabalho é desenvolvido (estudos quantitativos muitas vezes exigem equipes de trabalho interdisciplinares e volume expressivo de recursos financeiros). Cabe, pois, apostar em processos de investigação reflexivos, que atendam às exigências dos problemas de pesquisa, e conhecer as especificidades de cada tipo de abordagem, de modo a identificar suas potencialidades e a evitar críticas que careçam de fundamentação. 


\section{REFERÊNCIAS}

APPLE, M. W.; BALL, S. J.; GANDIN, L. A. (Org.). Sociologia da educação: análise internacional. Porto Alegre: Penso, 2013.

ASSOCIAÇÃO NACIONAL DE PÓS-GRADUAÇÃO E PESQUISA EM EDUCAÇÃO. GT14 - Sociologia da Educação. Rio de Janeiro: ANPEd, [201-]a. Disponível em: <http://www.anped.org.br/gruposde-trabalho/gt14-sociologia-da-duca\%C3\%A7\%C3\%A3o>. Acesso em: 23 fev. 2017.

ASSOCIAÇÃO NACIONAL DE PÓS-GRADUAÇÃO E PESQUISA EM EDUCAÇÃO. Reuniões Anuais. Rio de Janeiro: ANPEd, [201-]b. Disponível em: $<$ http://www.anped.org.br/reunioes-cientificas/nacional>. Acesso em: 23 fev. 2017.

BABBIE, E. Métodos de pesquisa de survey. Tradução de Guilherme Cezarino. Belo Horizonte: Editora da UFMG, 2001.

BAQUERO, M. A pesquisa quantitativa nas ciências sociais. Porto Alegre: Editora da UFRGS, 2009.

BOURDIEU, P. Le champ scientifique. Actes de la recherche en sciences sociales, n. 2-3, p. 88-104, jun. 1976.

BOURDIEU, P. Los usos sociales de la ciencia. Buenos Aires: Nueva Visión, 2003.

BOURDIEU, P. Para uma sociologia da ciência. Lisboa: Edições 70, 2008.

BOURDIEU, P.; WACQUANT, L. Una invitación a la sociología reflexiva. Buenos Aires: Siglo XXI, 2005.

CANDIDO, A. Tendências no desenvolvimento da sociologia da educação. In: PEREIRA, L.; FORAC$\mathrm{CHI}, \mathrm{M}$. Educação e sociedade. São Paulo: Editora Nacional, 1978. p. 7-18.

CÊA, G. S. dos S.; SILVA, C. F. da. Mosaicos das sociologias da educação no Brasil: mapeamento da produção do GT-14 da ANPEd na primeira década do século XXI. Quaestio, v. 17, n. 1, p. 215-241, maio 2015.

CHARLOT, B. A pesquisa educacional entre conhecimentos, políticas e práticas: especificidades e desafios de uma área de saber. Revista Brasileira de Educação, v. 11, n. 31, p. 07-18, jan./abr. 2006.

COSTA, M.; SILVA, G. M. D. da. Amor e desprezo: o velho caso entre sociologia e educação no âmbito do GT-14. Revista Brasileira de Educação, n. 22, p. 101-120, jan./abr. 2003.
DE LA FARE, M.; CARVALHO, I. C. de M. Ética e pesquisa em educação: tensões entre autonomia e regulação. In: SANTOS, L. H. S. dos; KARNOPP, L. B. (Org.). Ética e pesquisa em educação: questões e proposições às ciências humanas e sociais. Porto Alegre: Editora da UFRGS, 2017.

FERNANDES, F. O dilema educacional brasileiro. In: PEREIRA, L.; FORACCHI, M. Educação e sociedade. São Paulo: Nacional, 1978a. p. 414-441.

FERNANDES, F. Sociologia da educação como "sociologia especial”. In: PEREIRA, L.; FORACCHI, M. Educação e sociedade. São Paulo: Editora Nacional, 1978b. p. 6.

FERRARO, A. Quantidade e qualidade na pesquisa em educação, na perspectiva da dialética marxista. Pro-posições, v. 23, n. 1, p. 129-146, jan./abr. 2012.

FERREIRA, M. dos S. Os centros de pesquisas educacionais do INEP e os estudos em ciências sociais sobre a educação no Brasil entre as décadas de 1950 e 1960. In: REUNIÃO ANUAL DA ASSOCIAÇÃO NACIONAL DE PÓS-GRADUAÇÃO E PESQUISA EM EDUCAÇÃO, 30., 2007, Caxambu-MG. Anais... Caxambu-MG: ANPEd, 2007. Disponível em: <http://30reuniao.anped.org.br/ trabalhos/GT14-3097-Int.pdf.>. Acesso em: 25 fev. 2017

FLECK, L. To look, to see, to know. In: COHEN, R. S.; SCHNELLE, T. Cognition and fact: materials on Ludwik Fleck. Dordrecht, Holland: Reidel, 1986. p. 129-151.

GATTI, B. Estudos quantitativos em educação. Educação e Pesquisa, v. 30, n. 1, p. 11-30, jan./abr. 2004.

GATTI, B. Implicações e perspectivas da pesquisa educacional no Brasil contemporâneo. Cadernos de Pesquisa, n. 113, p. 65-81, jul. 2001.

GOUVEIA, A. J. Orientações teórico-metodológicas da sociologia da educação no Brasil. Cadernos de Pesquisa, n. 55, p. 63-67, nov. 1985.

INSTITUTO NACIONAL DE ESTUDOS E PESQUISAS EDUCACIONAIS ANÍSIO TEIXEIRA. História. Brasília, DF: INEP, 2015a. Disponível em: <http:// portal.inep.gov.br/historia>. Acesso em: 23 mar. 2017.

INSTITUTO NACIONAL DE ESTUDOS E PESQUISAS EDUCACIONAIS ANÍSIO TEIXEIRA. Saeb. Brasília, DF: INEP, 2017. Disponível em: <http:// portal.inep.gov.br/educacao-basica/saeb>. Acesso em: 25 fev. 2017 
INSTITUTO NACIONAL DE ESTUDOS E PESQUISAS EDUCACIONAIS ANÍSIO TEIXEIRA. Sobre a Anresc (Prova Brasil). Brasília, DF: INEP, 2015b. Disponível em: <http://portal.inep.gov.br/web/ guest/educacao-basica/saeb/sobre-a-anresc>. Acesso em: 25 fev. 2017.

MARRADI, A.; ARCHENTI, N.; PIOVANI, J. Metodología de las ciencias sociales. Buenos Aires: Emecé, 2007.

NEVES, C. E. B. Estudos sociológicos sobre educação no Brasil. In: MICELI, S. (Org.). O que ler na ciência social brasileira - 1970 - 2002. São Paulo: Sumaré; Brasília: CAPES, 2002. p. 351-437. v. 4.

OECD. PISA - Programme for International Student Assessment. Paris, 2017. Disponível em: <http:// www.oecd.org/pisa/aboutpisa/>. Acesso em: 25 fev. 2017.
OLIVEIRA, A.; SILVA, C. F. da. Mapeando a sociologia da educação no Brasil: análise de um campo em construção. Atos de Pesquisa em Educação, v. 9, n. 2, p. 289-315, maio/ago. 2014.

PLAISANCE, É.; VERGNAUD, G. As ciências da educação. Tradução de Nadyr Penteado e Odila Queiroz. São Paulo: Edições Loyola, 2003.

RAMOS ZINCKE, C. Cómo investigan los sociólogos chilenos en los albores del siglo XXI: paradigmas y herramientas del oficio. Persona y Sociedad, v. 19, n. 3, p. 85-119, 2005.

SILVA, T. T. da. A sociologia da educação entre o funcionalismo e o pós-modernismo: os temas e os problemas de uma tradição. Em Aberto, n. 46, abr.l jun. 1990. p. 03-12. 